\title{
Çalışma Sermayesi Etkinlik Ölçümünde İndeks Yöntemi: Teknoloji Şirketlerinde Bir Uygulama
}

DOI: 10.26466/opus. 909470

\author{
* \\ Ülkü Mazman İtik* \\ * Dr. Öğr. Üyesi, Cumhuriyet Üniversitesi, Sosyal Bilimler MYO, Sivas/Türkiye \\ E-Posta: umazman@cumhuriyet.edu.tr \\ ORCID: 0000-0003-2472-9093
}

Öz

Çalışma sermayesi yönetimi işletmelerin faaliyetini sürdürmesi için dönen varlıklara ne kadar yatırım yapılması gerektiği ve bu yatırımların hangi kaynaklarla finanse edilmesi gerektiği ile ilgilidir. Literatürde çalışma sermayesi yönetiminin ölçümünde finansal rasyoları kullanıldığ̆ çok sayıda çalışma mevcuttur. Bu çalı̧̧manın temel amacı, Borsa İstanbul (BIST) Teknoloji sektöründe faaliyet gösteren firmaların çalışma sermayesi etkinlik düzeyini İndeks Etkinlik Yöntemi ile ölçmektir. Bu amaca ulaşmak için Bhattacharya (1997) tarafindan geliştirilen Indeks yöntemi kullanılmıştır. Borsada işlem gören 12 adet şirketin 2009 -2019 yılları arası üçer aylık verileri kullanılarak kullanım indeksi, performans indeksi, etkinlik indeksi değerleri hesaplanmıştır. Çalışmanın sonuç kısmında, bütün şirketlerin indeks değerlerinin 1'den büyük olduğu yani dönen varliklara yapılan yatırımların satış hasılatını artırdı̆̆ tespit edilmiştir. Ayrıca kullanım indeksi açısından en yüksek verimliliğe sahip olan şirketin NETAŞ şirketi, performans indeks değeri açısından ALC şirketi, etkinlik indeksi bakımından ise yine ALC şirketinin ilk sırada olduğu tespit edilmiştir. Ayrıca mevcut şirketler içerisinde daha düşük seviyede çalışma sermayesi indeks değerine sahip olan şirketin ise tüm indeks ortalama değerlerinde, INDES şirketi olduğu sonucuna ulaşılmıştır.

Anahtar Kelimeler: Çalı̧̧ma Sermayesi Yönetimi, İndeks Yöntemi, Borsa İstanbul (BIST). 


\title{
Index Method in Efficiency Measurement of Working Capital: The Case of Technology Companies
}

*

\begin{abstract}
Working capital management is about how much businesses should invest in current assets in order to continue their activities and with what resources these investments should be financed. There are many studies in the literature in which financial ratios are used in the measurement of working capital management. The main purpose of this study is to measure the working capital efficiency level of companies operating in the technology sector in Borsa Istanbul (BIST) with the Index Efficiency Method. In order to achieve this goal, the Index method developed by Bhattacharya (1997) was used. The usage index, performance index and efficiency index values of 12 companies listed on the BIST were calculated using quarterly data between 2009 and 2019. In the conclusion part of the study, it has been determined that the index values of all companies are greater than 1 , and as a result, investments made in current assets increase the sales revenue. In addition, it was determined that the company with the highest efficiency in terms of usage index is NETAŞ company, on the other hand ALC company is in the first place in terms of performance index value and efficiency index. Moreover, it was concluded that the company with a lower working capital index value among the existing companies is INDES company in all index average values.
\end{abstract}

Keywords: Capital Management, Index Method, Istanbul Stock Exchange. 


\section{Giriş}

Uluslararası rekabetin yoğun olarak yaşandığı günümüzde sermaye sahipleri adına yatırım ve finansman kararları alan işletmelerin, çalışma sermayesi yönetimini etkin ve verimli şekilde sürdürmeleri büyük önem arz etmektedir. Sermaye bütçelemesi, uzun vadeli finansal kararlar üzerinde etkili olurken çalışma sermayesi yönetimi ise kısa vadeli yatırım kararları ve bu kararların finansmanı konusuna ağırlık vermektedir (Sharma ve Kumar, 2011, s.160). Çalışma sermayesi, işletmenin sahip olduğu dönen varlıklar içerisinde nakde çevrilebilme gücü, yani likiditesi yüksek olan kalemleri ifade etmektedir (Brigham ve Houston, 2007, s.63).Bu kalemler, hazır değerler grubunda yer alan nakit ve nakit benzeri varlıklar, menkul değerler, alacaklar ve stok kalemleridir. İşletmelerin faaliyetlerini aralıksız bir şekilde sürdürmeleri mal ve hizmet üretimlerini devam ettirebilmeleri, ayrıca oluşabilecek risklerin en az seviyeye indirilmesi için çalışma sermayesine yapılan yatırımlar önem arz etmektedir (Toraman ve Sönmez, 2015, s.23). Ayrıca çalışma sermayesi verileri işletmelere kredi veren finans kuruluşları açısından da önemli bir kriterdir. Finans kurumları, yüksek düzeyde çalışma sermayesine sahip olan firmaları, kredibilitesi yüksek firma niteliğine sahip firmalar olarak değerlendirmektedirler (Öz ve Güngör, 2007, s.320).

Etkin bir çalışma sermayesi yönetiminde, firmanın kısa vadeli yükümlülüklerini yerine getirirken meydana gelebilecek risklerin ortadan kald1rılması, diğer taraftan ise cari varlıklara optimum yatırım yapılması hedeflenmektedir. Ayrıca yöntem aktif ve pasiflerin en verimli şekilde kontrol edilmesini kapsamaktadır (Eljelly, 2004, s.48). Çalışma sermayesi ile ilgili bir diğer konuda optimal oranda çalışma sermayesinin belirlenmesidir. Ancak optimal çalışma sermayesinin belirlenmesi, bazı zorlukları bünyesinde barındırmaktadır ( Göker, 2018, s.70). Örneğin firmanın içinde bulunduğu sektörün yapısı, rekabet gücü, teknolojik altyapı, kredi politikaları gibi birçok değişkenden dolayı optimal çalışma sermayesini belirlemek oldukça zordur (Aytürk ve Yanık, 2015, s.161). İşletmelerin olması gerekenden daha az düzeyde çalışma sermayesine sahip olması likidite durumları zayıflarken, gereğinden fazla çalışma sermayesine sahip olması ise karlılığın azalması ile sonuçlanabilir. Bu sebeple işletmelerin optimum çalışma sermayesi konusuna önem vermeleri gerekmektedir. 
Çalışma sermayesi yönetimi ile ilgili yapılan çalışmalar incelendiğinde çalışma sermayesi yönetimine yönelik farklı çalışmalara rastlanmıştır. Sakarya (2008), Yücel ve Kurt (2002), gibi pek çok yazarın çalışmalarında stok devir hızı, alacakların ortalama tahsilat süresi ve kısa vadeli kaynakları ödeme süresi gibi verilerle nakit dönüşüm süresi hesaplanmış ve bu veriler çalışma sermayesi yönetiminin göstergesi olarak kabul edilmiştir. Bu çalışmalardan farklı olarak, Güler ve Konuk (2019), Göker (2018) ise çalışmalarında, çalışma sermeyesi etkinlik düzeyini Bhattacharya (1997) tarafından geliştirilen Indeks yöntemi ile ölçmüş ve ulusal literetüre katkı sağlamışlardır.

Çalışmanın amacı, BIST' de faaliyet gösteren teknoloji şirketlerinin çalışma sermayesi yönetim etkinliklerini Bhattacharya (1997) tarafından geliştirilen Indeks yöntemi ile hesaplamak ve literatüre katkı sağlamaktır. Teknoloji sektörü, teknolojik asıllı mal ve hizmetlerin üretilmesi, araştırılması, geliştirilmesi veya dağıtımını esas alan bir sektördür. Sektördeki şirketler, elektronik ürünlerle birlikte yazılım, bilgisayar, teknolojik tüketici ürünleri gibi birçok ürün ve hizmetlerin üretimi konusunda uzmanlaşmışlardır. (kalkinmakutuphanesi.gov.tr). Çalışmada BİST'de kayıtlı 12 adet şirketin 2009 ile 2019 yılları arasında üçer aylık verileri kullanılmıştır. Veriler KAP' dan elde edilmiştir. Araştırmada 3 adet indeks kullanılmıştır. Bunlar etkinlik indeksi, performans ve kullanım indeksidir. Çalışmanın uygulama kısmında her bir şirketin indeks değerleri bulunmuş çıkan sonuçlar yöntem doğrultusunda yorumlanmıştır.

\section{Literatür}

Çalışma indeksi ile ilgili yapılan literatür taramasında, uluslararası kapsamda çalışmalar tespit edilmiş olup, ulusal anlamda çok sayıda çalışmaya rastlanmamıştır. Ramachandran ve Janakiraman (2009), çalışmalarında Bhattacharya (1997)'nın modeline dayanarak çalışma sermayesi etkinlik düzeyini üç farklı indeks olan performans indeksi (PI), faydalanma indeksi (UI) ve etkinlik indeksini (EI) hesaplayarak analizlerini gerçekleştirmişlerdir. 1997-2006 yılı verilerini ele alarak yapmış oldukları çalışmada, Hindistan borsasında kâğıt sektöründe faaliyet gösteren 30 firmayı incelemişlerdir. Şirketlerin büyük çoğunluğunun bazı yıllarda PI ve EI de- 
ğerinin 1'den küçük olduğunu, bazı yıllarda ise şirketlerin çalışma sermayesini etkin olarak kullandıklarını, fakat sektörün istikrarı sağlayacak politikalar üretmesi gerekliliğine vurgu yapmışlardır (Ramachandran ve Janakiraman, 2009, s.73 ). Sharma ve Kumar (2011), çalışmalarında işletme sermayesi ile kârlılık düzeyi arasındaki ilişkiyi çoklu regresyon analizi kullanarak incelemişlerdir. Çalışma Bombay Borsası'nda faaliyet gösteren 263 şirketin 2000-2008 yıllarındaki verileri kullanılarak gerçekleştirilmiştir. Analiz sonucunda borç ödeme süresi, stok tutma süresi ile kârlılık arasında negatif; alacak tahsil süresi,nakit dönüş süresi ile kârlılık arasında pozitif ilişki tespit edilmiştir (Sharma ve Kumar, 2011, s.161).

Afza ve Nazir, (2011), çalışmalarında, Pakistan' da çimento sektöründe faaliyet gösteren 22 adet işletmenin, 1988-2009 yılları arası verilerinden yararlanarak, işletme sermayesi yönetiminin verimlilik düzeyini ölçmeyi amaçlamışlardır. Analize 22 firmanın 18 yıllık verileri dâhil edilmiştir. Çalışmanın sonuç kısmında firmaların 18 yıl boyunca verimlilik indeks değerinin 1'den büyük olduğu dolayısı ile firmaların etkin bir şekilde çalışma sermayesi yönetimini kullandıkları tespit edilmiştir (Afza ve Nazir, 2011, s.228 ). Kaur ve Singh (2013), çalışmalarında Bombay Menkul Kıymetler Piyasası İndeksinde aktif olarak faaliyet gösteren 14 adet üretici firmanın 2000-2010 yılları arasındaki performans indeksi (PI), faydalanma indeksi (UI) ve etkinlik indeksini (EI) hesaplayarak analizlerini gerçekleştirmişlerdir. Çalışmada her bir şirketin indeks değerlerinin en düşük ve en yüksek değerleri tespit edildikten sonra bu değerlere sahip olan şirketler belirlenmiştir. Çalışmanın sonuç kısmında çalışmaya dâhil edilen iki şirketin dişında diğer şirketlerin etkinlik indeksinin 1'den büyük olduğu, ayrıca 2004 yılında bütün şirketlerin çalışma sermayesi etkinlik indeksinin birden büyük olduğu sonucuna ulaşılmıştır (Kaur ve Singh, 2013, s.347).

Kaur (2014),çalışmasında Bombay Menkul Kıymetler Piyasası İndeksinde, sağlık sektöründe aktif olarak faaliyet gösteren 13 adet şirketin 2000-2014 yılları arasındaki, performans indeksi (PI), faydalanma indeksi (UI) ve etkinlik indeksi (EI) olmak üzere çalışma sermayesi indeks değerine ulaşmıştır. Ardından firmaların etkinlik düzeylerini sektör düzeyine getirme başarısını regresyon analizi ile tespit etmiştir. Çalışmanın sonucunda analize dâhil edilen 2 adet firmanın dışındaki tüm firmaların çalı̧̧ma sermeyesini etkin şekilde kontrol ettikleri sonucuna ulaşmıştır. Ayrıca, sektördeki firmaların çalışma sermayesi yönetimi etkinlik düzeyine 
ulaşabilmeleri için faaliyetlerini daha iyi planlamaları gerektiğine yönelik önerilerde bulunmuştur (Kaur, 2014, s.57).

Kasiran F. W., Mohamad N. A., Chin O. (2016), çalışmalarında Malezya'da faaliyet gösteren 24 adet küçük ve orta büyüklükteki firmanın 2010-2013 yılları arasındaki çalışma sermayesi etkinlik düzeylerini Bhattacharya (1997)'nin geliştirdiği model ile hesaplamışlardır. Çalışmada çalışma sermayesi etkinlik indekslerinden olan, etkinlik indeksi kullanılmıştır. Çalışmanın sonuç kısmında firmaların tamamının UI değerinin 1'den büyük olduğu, bir firma dışındaki diğer firmaların PI değerlerinin 1'in altında olduğu, ayrıca EI değerinin ise birçok firma için 1'in altında bir değere sahip olduğu sonucuna ulaşılmıştır (Kasiran, Mohamad, Chin, 2016, s.300). Kendirli ve Çağıran (2016),çalışmalarında BIST' da faaliyet gösteren turizm şirketlerinin 2010-2014 yılları arası verilerini analiz ederek işletme sermayesi ve karlılık arasındaki ilişkiyi analiz etmişlerdir. Buna ek olarak çalışmada nakit döngüsü aracılığı ile işletme sermayesi yönetimi ölçülmüştür. Çalışmada yöntem olarak regresyon analizi yöntemi uygulanmıştır. Çalışmanın bulgular kısmında ise işletme sermayesi ile aktif karlılık arasında pozitif yönlü ve anlamlı bir ilişki tespit etmişlerdir (Kendirli ve Çankaya, 2016, s.67).

Göker (2018), çalışmasında BIST'da işlem gören 24 adet gida sektörü firmasının 2010-2017 döneminde çalışma sermayesi etkinlik düzeylerini tespit etmeye çalışmıştır. Çalışmada Bhattacharya (1997) tarafından geliştirilen çalışma sermayesi yönetim indeksi kullanılmış olup, çalışmanın sonuç kısmında firmaların indeks değerlerinin 1'in üzerinde olduğu yani etkin bir şekilde çalışma sermayesi yönetimini gerçekleştirdiklerini tespit etmiştir ( Göker, 2018, s.71). Erem Ceylan (2020), çalışmasında çalışma sermayesi yönetiminde uygulama alanı bulan indeks yönteminin teorik alt yapısını incelemiştir. Ardından Borsa İstanbul' da perakende sektöründe işlem gören firmaların işletme sermayesi yönetim ve verimlilik seviyelerini tespit etmek amacıyla indeks yöntemini kullanmıştır. Çalışmanın sonuç kısmında perakende sektöründe faaliyet gösteren firmaların etkin bir şekilde işletme sermayesi yönetimini kullandıkları tespit edilerek bazı önerilerde bulunulmuştur (Erem Ceylan, 2020, s.244).

\section{Metodoloji}


Çalışmanın Amacı: Çalışma, BIST' da işlem gören teknoloji şirketlerinin çalışma sermayesi etkinlik düzeyini, Bhattacharya (1997) tarafından geliştirilmiş olan “Çalışma Sermayesi Yönetim İndeksi” ile ölçmek ve literatüre katkı sağlaması amacıyla hazırlanmıştır.

Çalışmanın Yöntemi: Çalışmanın amacını gerçekleştirmek için BİST’ da işlem gören 19 adet şirketten 12 adet teknoloji şirketinin 2009-2019 yılı üçer aylık verileri ele alınarak, Performans İndeksi (PI), Kullanım İndeksi (UI), ve Etkinlik İndeksi (EI) elde edilmiştir. İndeks yönteminde kullanılan üç değişkenden biri olan performans indeksi, varlıklar içerisindeki çeşitli hesapların ortalama performanslarını gösterirken, kullanım indeksi ise cari varlıklardan faydalanarak satışları artırma yeteneğini ölçer, etkinlik indeksi ise performans ve kullanım indekslerinin çarpılması sonucu elde edilen bir göstergedir (Bhattacharya, 1997, s.25). Çalışmaya dahil edilmeyen 7 adet şirketin verilerinde söz konusu yıllara ait verilerde eksikliklerin olması, bazı şirketlerin ise söz konusu yıllarda BIST' e kayıtlı olmamaları sebebi ile kapsam dışı bırakılmıştır. Çalışmanın uygulama kısmında her bir indeksi hesaplamak için 480 adet, toplamda 1440 adet veri elde edilmiş, elde edilen veriler Tablo 3'e aktarılmıştır. Çalışmaya dâhil edilen şirketlerin isimleri ve kodları Tablo 1' de listelenmiştir.

Tablo 1. 2019 Yılı BIST’ da Faaliyet Gösteren ve Analize Dâhil Edilen Şirketler

\begin{tabular}{lll}
\hline & Şirket Adi & Şirket Kodu \\
\hline 1 & Alcatel Lucent Teletaş Telekomünikasyon A.Ş. & (ALCTL) \\
2 & Arena Bilgisayar Sanayi ve Ticaret A.Ş. & (ARENA) \\
3 & Armada Bilgisayar Sistemleri Sanayi Ve Ticaret A.Ş. & (ARMDA) \\
4 & Aselsan Elektronik Sanayi Ve Ticaret A.Ş. & (ASELS) \\
5 & Datagate Bilgisayar Malzemeleri Ticaret A.Ş & (DGATE) \\
6 & Despec Bilgisayar Pazarlama ve Ticaret A.Ş. & (DESPC) \\
7 & İndeks Bilg. Sistemleri Müh. Sanayi Ve Ticaret A.Ş. & (INDES) \\
8 & Karel Elektronik Sanayi ve Ticaret A.Ş. & (KAREL) \\
9 & Link Bilg.Sis. Yaz. ve Donanım Sanayi ve Tic. A.Ş. & (LINK) \\
10 & Logo Yazılım Sanayi ve Ticaret A.Ş. & (LOGO) \\
11 & Netaş Telekomünikasyon A.Ş. & (NETAS) \\
12 & Plastikkart Akıllı Kart İletişim Sis. San. ve Ticaret A.Ş. & (PKART) \\
\hline
\end{tabular}

Kaynak: wwww.kap.org.tr (Kamuyu Aydinlatma Platformu)

Performans İndeksi (PI), işletmenin varlık yapısı içerinde önemli bir payı olan dönen varlıklar içerinde yer alan hesap kalemlerinin ortalama 
performanslarını gösteren bir indekstir. İndeks, çalışma kapsamına alınan her bir şirketin dönen varlık alt hesap kalemlerinin performansını ölçmek için kullanılmıştır. Çalışmada dönen varlık kalemlerinden olan dört alt başlık, nakit ve nakit benzerleri, ticari alacaklar, stoklar ve diğer dönen varlıklar, indeks hesaplanırken analize dâhil edilmiştir. Performans indeksi hesaplanırken kullanılan formül Tablo 2' de yer almaktadır. Performans indeksi,grup üyelerinin tek tek ve bireysel performanslarını dikkate alan bir indekstir (Güler ve Konuk, 2019, s.37). Kullanım İndeksi (UI) ise, işletmenin dönen varlıklarını kullanarak, işletmenin satışlarını ne derecede artırdığını ölçen indeks değeridir. Kullanım indeksi değerlerinin 1'den büyük olması arzu edilir. Kullanım indeksinin birden büyük olması çalışma sermayesinin etkin bir şekilde yönetildiği anlamına gelmektedir. Kullanım indeksi hesaplanırken kullanılan formül Tablo 2' de yer almaktadır. Kullanım indeksi grubun toplam performansını ifade etmektedir (Güler ve Konuk, 2019, s.36). Etkinlik indeksi (EI) ise, çalışma sermayesinin etkin kullanılıp kullanılmadığı ile ilgili nihai göstergedir. Etkinlik indeksi, performans ve kullanım indeksinin çarpım sonucu elde edilen bir değeri ifade etmektedir. Etkinlik indeksi değerinin birden büyük olması, arzu edilen bir durumdur. İndeks değerinin 1'den büyük olması çalışma sermayesinin etkin bir şekilde yönetildiğinin göstergesidir ( Göker, 2018, s.74).

Tablo 2. Çalışma Sermayesi İndeks yönteminde Kullanılan Formüller

\begin{tabular}{|c|c|}
\hline Değişkenler & Hesaplamalar \\
\hline \multirow{5}{*}{$\begin{array}{l}\text { Performans } \\
\text { (PI), }\end{array}$} & $W_{\text {it-1 }}-W_{\text {it }} / N$ \\
\hline & Is = Satışlar cari dönem / Satışlar önceki dönem \\
\hline & $\mathrm{W}_{\mathrm{i}}=$ Dönen varlık alt hesap grubunun tutarı \\
\hline & $\begin{array}{l}W_{i t}=i \text { şirketinin } t \text { dönemindeki dönen varlık alt hesap grubunun } \\
\text { tutarı }\end{array}$ \\
\hline & $N=$ Dönen varlık alt hesap grubu sayısı \\
\hline Kullanım İndeksi (UI), & $\begin{array}{l}\text { A Önceki dönem / A Cari dönem } \\
\text { Satışlar) }\end{array}$ \\
\hline Etkinlik İndeksi (EI) & Performans İndeksi (PI)* Kullanım İndeksi (UI), \\
\hline
\end{tabular}

Kaynak: Güler ve Konuk (2019), çalışmalarından derlenerek hazırlanmıştır 


\section{Bulgular}

Çalışmanın bu bölümünde, elde edilen bulgular yer almaktadır. Araştırmanın amacına ulaşmak için 12 adet şirketin 2009-2019 yılı, üçer aylık verilerine Tablo 1'deki formüller uygulanmış ve Excel ortamında yapılan hesaplamalar sonucu Tablo 3 oluşturulmuştur. Ardından elde edilen veriler sonuç kısmında yorumlanmıştır. Tablo 2'de örnek işletmenin temel mali tablolarından elde edilen verilerle, Performans indeksi (PI), Kullanım İndeksi (UI), ve Etkinlik İndeksi (EI) ‘nin nasıl elde edildiği örneklendirilmiştir.

Tablo 2. Analize Dâhil Edilen Bir İşletmenin İndeks Değerleri Uygulama Örneği

\begin{tabular}{|c|c|c|c|c|c|c|}
\hline & \multirow[b]{2}{*}{ DÖNEM } & A & B & $\mathrm{C}$ & D & $\mathbf{E}$ \\
\hline & & $\begin{array}{l}20094 . \\
\text { Çeyrek }\end{array}$ & $\begin{array}{l}20101 . \\
\text { Çeyrek }\end{array}$ & $\begin{array}{l}20102 . \\
\text { Çeyrek }\end{array}$ & $\begin{array}{l}20103 . \\
\text { Çeyrek }\end{array}$ & $\begin{array}{l}20104 . \\
\text { Çeyrek }\end{array}$ \\
\hline 1 & $\begin{array}{l}\text { Dönen Varlıklar } \\
\text { (TL) }\end{array}$ & 184.802.492 & 148.635 .907 & 149.529 .409 & 158.510 .321 & 196.070.169 \\
\hline 2 & $\begin{array}{l}\text { Nakit ve Nakit Ben- } \\
\text { zerleri }\end{array}$ & 32.162 .520 & 22.510 .686 & 12.438 .935 & 1.729 .762 & 17.606.117 \\
\hline 3 & Ticari Alacaklar & 126.647 .597 & 89.786 .566 & 100.952 .978 & 107.541 .079 & 126.605 .635 \\
\hline 4 & Stoklar & 20.407.231 & 18.509.339 & 18.720 .236 & 26.268 .816 & 27.721 .899 \\
\hline 5 & $\begin{array}{l}\text { Diğer Dönen Var- } \\
\text { liklar }\end{array}$ & 5.554 .758 & 17.736 .394 & 17.417 .260 & 22.970 .664 & 23.831 .823 \\
\hline 6 & Net Satışlar (TL) & 352.830 .482 & 66.988 .301 & 127.081 .961 & 176.298 .766 & 263.459 .079 \\
\hline 7 & Kullanım İndeksi & & (A1/A6) & (B1/B6) & $(\mathrm{C} 1 / \mathrm{C} 6)$ & (D1/D6) \\
\hline 8 & $\begin{array}{l}\text { Performans İn- } \\
\text { deksi (PI) }\end{array}$ & & $\begin{array}{l}(\mathrm{B} 1 / \mathrm{B} 6) \\
(\mathrm{B} 6 / \mathrm{A} 6)^{*}(( \\
\mathrm{A} 2 / \mathrm{B} 2)+ \\
(\mathrm{A} 3 / \mathrm{B} 3)+ \\
(\mathrm{A} 4 / \mathrm{B} 4)+ \\
(\mathrm{A} 5 / \mathrm{B} 5)) / \\
4)\end{array}$ & $\begin{array}{l}(\mathrm{C} 1 / \mathrm{C} 6) \\
(\mathrm{C} 6 / \mathrm{B} 6)^{*}((\mathrm{~B} \\
2 / \mathrm{C} 2)+ \\
(\mathrm{B} 3 / \mathrm{C} 3)+ \\
(\mathrm{B} 4 / \mathrm{C} 4)+ \\
(\mathrm{B} 5 / \mathrm{C} 5)) / \\
4)\end{array}$ & $\begin{array}{l}(\mathrm{D} 1 / \mathrm{D} 6) \\
(\mathrm{D} 6 / \mathrm{C} 6)^{*}(( \\
\mathrm{C} 2 / \mathrm{D} 2)+ \\
(\mathrm{C} 3 / \mathrm{D} 3)+ \\
(\mathrm{C} 4 / \mathrm{D} 4)+ \\
(\mathrm{C} 5 / \mathrm{D} 5)) / \\
4)\end{array}$ & $\begin{array}{l}(\mathrm{E} 1 / \mathrm{E} 6) \\
(\mathrm{E} 6 / \mathrm{D} 6)^{*}(( \\
\mathrm{D} 2 / \mathrm{E} 2)+ \\
(\mathrm{D} 3 / \mathrm{E} 3)+ \\
(\mathrm{D} 4 / \mathrm{E} 4)+ \\
(\mathrm{D} 5 / \mathrm{E} 5)) / \\
4)\end{array}$ \\
\hline 9 & $\begin{array}{l}\text { Etkinlik İndeksi } \\
\text { (EI) }\end{array}$ & & $\mathrm{B} 7 * \mathrm{~B} 8$ & $\mathrm{C}^{*} \mathrm{C} 8$ & $\mathrm{D} 7{ }^{*} \mathrm{D} 8$ & $\mathrm{E} 7{ }^{*} \mathrm{E} 8$ \\
\hline & $\begin{array}{ll}0,21 & B 8=0,19 \\
1,21 & \text { D8 }=1,18\end{array}$ & $\begin{array}{l}C 7=1,74 \\
E 7=1,42\end{array}$ & $\begin{array}{l}1,99 \\
1,78\end{array}$ & & & \\
\hline
\end{tabular}


Tablo 2' de yer alan hesaplamalar 12 adet şirket için ve 2009-2019 yılları arası üçer aylık dönemleri için ayrı ayrı hesaplanmış ve Tablo 3 oluşturulmuştur. Tablo 3'de her bir işletmenin Performans İndeksi (PI), Kullanım İndeksi (UI), ve Etkinlik İndeksi (EI) değerleri, şirket bazında yer almaktadır.

Tablo 3. BIST' da İşlem Gören Teknoloji Şirketlerinin 2009-2019 Yılları Arası Çalışma Sermayesi Etkinlik Indeksi Değerleri Tablosu

\begin{tabular}{lllllllllll}
\hline \multirow{2}{*}{ İşletme Kod } & \multicolumn{2}{c}{ Kullanım İndeksi (UI) } & \multicolumn{3}{c}{ Performans İndeksi (PI) } & \multicolumn{3}{c}{ Etkinlik İndeksi (EI) } \\
\cline { 3 - 10 } & & Mean & Min & Max & Mean & Min & Max & Mean & Min & Max \\
\hline 1 & (ALCTL) & 1,35 & 0,13 & 2,96 & 1,88 & 0,12 & 9,69 & 3,53 & 0,02 & 25,63 \\
2 & (ARENA) & 1,23 & 0,25 & 2,32 & 1,34 & 0,23 & 2,53 & 2,06 & 0,06 & 5,56 \\
3 & (ARMDA) & 1,23 & 0,24 & 2,22 & 1,49 & 0,23 & 3,73 & 2,25 & 0,06 & 5,82 \\
4 & (ASELS) & 1,32 & 0,16 & 2,53 & 1,41 & 0,16 & 2,75 & 2,37 & 0,03 & 6,23 \\
5 & (DGATE) & 1,23 & 0,23 & 2,48 & 1,52 & 0,23 & 4,45 & 2,37 & 0,05 & 10,37 \\
6 & (DESPC) & 1,27 & 0,20 & 2,22 & 1,50 & 0,17 & 6,38 & 2,42 & 0,03 & 11,44 \\
7 & (INDES) & 1,23 & 0,26 & 2,24 & 1,28 & 0,23 & 2,68 & 2,02 & 0,07 & 6,02 \\
8 & (KAREL) & 1,25 & 0,21 & 2,19 & 1,38 & 0,19 & 2,92 & 2,18 & 0,04 & 6,37 \\
9 & (LINK) & 1,30 & 0,03 & 2,26 & 1,47 & 0,20 & 3,71 & 2,37 & 0,01 & 6,41 \\
10 & (LOGO) & 1,28 & 0,24 & 4,04 & 1,49 & 0,20 & 6,12 & 2,67 & 0,05 & 24,73 \\
11 & (NETAS) & 1,40 & 0,16 & 2,96 & 1,63 & 0,16 & 4,73 & 3,02 & 0,02 & 9,99 \\
12 & (PKART) & 1,26 & 0,24 & 2,26 & 1,48 & 0,21 & 3,26 & 2,34 & 0,05 & 7,34 \\
\hline
\end{tabular}

Araştırmanın sonuçlarını şirket bazında ve her bir indeks için ayrı ayrı değerlendirdiğimizde, Kullanım İndeksi (UI) ortalama değerinin, 11 kodlu NETAŞ şirketinde en yüksek $(1,40)$, ortalama indeks değerine sahip olduğu, 1 kodlu ALC şirketinin ise 1,35 değeri ile ikinci sırada, 4 kodlu ASELS şirketinin ise üçüncü sırada yer aldığ tespit edilmiştir. En düşük kullanım indeks değerine sahip olan şirketler ise birden fazla olup $(1,23)$ indeks değeri ile sırasıyla ARENA, ARMDA, DGATE, INDES şirketleri olduğu görülmektedir. Kullanım indeksi değerinin birden büyük olması şirketlerin dönen varlıklarına bir bütün olarak yatırım yaptıkları takdirde, işletmenin satış hasılatını artırdığı anlamına gelmektedir. Şirketlerin tamamı çalışma sermayesi yönetiminde başarılı olsalar da NETAŞ, ALC, ve ASELS şirketlerinin diğer şirketlere oranla daha ön planda oldukları ve çalışma sermayelerini daha etkin kullandıkları söylenebilir.

Performans indeks değerini kullanım indeksinden ayıran özellik, kullanım indeks değeri dönen varlıklara yapılan yatırımları bir bütün olarak ele alırken, performans indeks değeri ise dönen varlık alt başlıklarına ya- 
pılan yatırımların kendi içinde verimli olup olmadığını ölçen indeks değeridir. Performans İndeksi (PI) ortalama değerinin, 1 kodlu ALC şirketinde en yüksek $(1,88)$, ortalama indeks değerine sahip olduğu, NETAŞ şirketinin ise $(1,63)$ ortalama değer ile ikinci sırada, olduğu tespit edilmiştir. En düşük performans indeks değerine sahip olan şirket ise $(1,28)$ indeks değeri ile İNDES şirketinin olduğu tespit edilmiştir. Performans indeks değerleri ortalamalarına bir bütün olarak baktığımızda tüm şirketlerin ortalama değerinin birden büyük olduğu tespit edilmişidir. Bu durum şirketlerin tamamının dönen varlık alt gruplarına doğru oranda yatırım yaptığı ve yapılan yatırmaların satış hasılatını artırdığı anlamına gelmektedir. Ancak göreceli olarak şirketlerin birbirlerine göre üstünlükleri söz konusu olduğu tespit edilmiştir.

Etkinlik indeks değeri, diğer iki indeksin sonuçlarından elde edilen nihai bir indeks değeridir. Etkinlik indeks değeri hem dönen varlıkların toplam olarak, hem de dönen varlık grubunda yer alan her bir kalemin ayrı ayrı etkin ve verimli kullanılıp kullanılmadığını ifade etmektedir. Etkinlik indeks değerini bir bütün olarak değerlendirdiğimizde tüm şirketlerin indeks değerleri ortalamalarının 1'den büyük ve tamamının 2 ve daha fazla bir değere sahip olduğu görülmektedir. Bu durum Bhattacharya (1997) tarafından geliştirilen Indeks Yönteminin gerekli kıldığı şartı fazlasıyla yerine getirdiği anlamına gelmektedir. Şirketlerin hem dönen varlıklara bir bütün olarak hem de kalem bazında doğru yatırımlar yaptığı ve yapılan yatırımların satışlara olumlu olarak yansıdığı anlamına geldiğini göstermektedir. Çalışmaya konu olan şirketlerin, etkinlik indeks değerlerini şirket bazında incelediğimizde ALC şirketinin $(3,53)$ ortalama indeks değeri ile birinci sırada yer aldığı, NETAŞ şirketini ise $(3,02)$ ortalama indeks değeri ile ikinci sırada yer aldığı görülmektedir. İNDES şirketi ise kullanım performans indeks değerinde olduğu gibi en düşük indeks ortalamasına $(2,02)$ sahip olan şirket olduğu tespit edilmiştir. İNDES şirketi çalışmaya konu olan şirketler içerisinde diğer şirketlere oranla daha az verimlilikte, çalışma sermayesi yönetimini gerçekleştiren şirket olarak değerlendirilmiştir. 


\section{Sonuç}

Yapılan bu çalışma BIST' da işlem gören 12 adet şirketin çalışma sermayesi yönetim etkinliğini, Bhattacharya (1997) tarafından geliştirilmiş olan "Çalışma Sermayesi Etkinlik İndeksi" ile ölçülmesi amacı ile hazırlanmıştır. Çalışmada BIST' da işlem gören 12 adet şirketin 2009-2019 yılı üçer aylık verileri ele alınarak kullanım indeksi, performans indeksi ve etkinlik indeksi, değerleri hesaplanmıştır. Çalışmadan elde edilen bulgular şu şekildedir.

Araştırma kapsamına dâhil edilen şirketlerin tamamının kullanım indeksi ortalaması, performans indeksi ve etkinlik indeksi ortalamalarına bir bütün olarak bakıldığında, tüm değerlerinin 1'den büyük olduğu tespit edilmiştir. Bu sonuç teknoloji şirketlerinin tamamının çalışma sermayesi yönetiminde başarılı olduğu ve dönen varlık kalemlerine bir bütün olarak veya tek bir kaleme yatırım yapıldığı takdirde yapılan bu yatırımların satış hasılatını artırdığı anlamına gelmektedir.

Kullanım İndeksi (UI) ortalama değerinin, 11 kodlu NETAŞ şirketinde en yüksek (1,40), ortalama indeks değerine sahip olduğu, ALC şirketinin ise $(1,35)$ değeri ile ikinci sırada, ASELS şirketinin ise üçüncü sırada yer aldığ tespit edilmiştir. En düşük kullanım indeks değerine sahip olan şirketler ise birden fazla olup $(1,23)$ indeks değeri ile sirasıyla ARENA, ARMADA, DGATE, INDES şirketleri olduğu görülmektedir. Kullanım indeksi değerinin 1'den büyük olması şirketlerin dönen varlıklarına bir bütün olarak yatırım yaptıkları takdirde işletmenin satış hasılatını artırdığı anlamina gelmektedir.

Performans İndeksi (PI) ortalama değerinin, ALC Şirketinde en yüksek $(1,88)$ ortalama indeks değerine sahip olduğu, NETAŞ şirketinin ise $(1,63)$ ortalama değer ile ikinci sırada, olduğu tespit edilmiştir. En düşük performans indeks değerine sahip olan şirket ise $(1,28)$ indeks değeri ile INNDES şirketi olduğu tespit edilmiştir. Performans indeks değerleri ortalamalarına bir bütün olarak baktığımızda tüm şirketlerin ortalama değerinin 1'den büyük olduğu tespit edilmişidir. Bu durum şirketlerin tamamının dönen varlık alt gruplarına doğru oranda yatırım yaptığı ve yapılan yatırmaların satış hasılatını artırdığı anlamına gelmektedir. 
Etkinlik indeksi değeri hem dönen varlıkların toplam olarak hem de dönen varlıklar grubunda yer alan her bir kalemin ayrı ayrı etkin ve verimli kullanılıp kullanılmadığını ifade etmektedir. Etkinlik indeks değeri 1 'den büyük ve tamamının 2 ve daha fazla düzeyde olduğu görülmektedir. Çalışmaya konu olan şirketlerin etkinlik indeks değerlerini şirket bazında incelediğimizde ALC şirketinin $(3,53)$ ortalama indeks değeri ile birinci sırada yer aldığı, NETAŞ şirketini ise $(3,02)$ ortalama indeks değeri ile ikinci sırada yer aldığı görülmektedir. İNDES şirketi ise kullanım ve performans indeks değerinde olduğu gibi en düşük indeks ortalamasına sahip olan şirkettir.

Teknoloji sektörünün 2009 ile 2019 yılları arasındaki genel eğilimi çalışmanın bulgularını destekler niteliktedir. Sektörün pazar büyüklüğü 2012 yılında 54,8 milyar TL düzeyinden,2018 yılında 11,7 milyar TL düzeyine 2019 yılında ise 154,9 TL düzeyine yükselmiştir. Teknoloji sektörünün yarattı̆̆ katma değerde önemli bir sevidedir. Türkiye' de teknoloji ve bilişim sektörünün 1 birim büyümesi, toplam ekonomiye 1,8 birimlik katkı sağlamaktadır. Bu durum yapılan yatırımların sektöre ve ekonomiye olan katkısını göstermektedir (Bilişim ve Sektör Raporu, 2019, s.14). Yatırımcılar açısından değerlendirme yapıldığında ise teknoloji ve bilişim sektörü gösterdiği büyüme eğilimi açısından cazip sektörler arasında olup sektör yatırım yapılacak ilk 5 sektör arasında yer almaktadır (hurriyet.com.tr).

Çalışma, teknoloji sektöründe faaliyet gösteren firmaların 2009-2019 yılları arasındaki verileri esas alınarak, literatüre katkı sağlaması umuduyla hazırlanmıştır. Bundan sonraki çalışmalarda sektör karşılaştırması yapılabilir veya iki şirketin kıyaslanması şeklinde çalışmalar yapılabileceği gibi çalışma dönemleri de genişletilebilir. 
EXTENDED ABSTRACT

\section{Index Method in Efficiency Measurement of Working Capital: The Case of Technology Companies \\ Ülkü Mazman İtik Cumhuriyet University}

Working capital management is related to how much investment should be made in current assets in order for businesses to continue their activities and with which resources these investments should be financed. In the literature, there are many studies in which financial ratios have been used in the measurement of working capital management.

The main purpose of this study is measuring the working capital efficiency level of companies operating in the Technology sector of Borsa Istanbul (BIST) with the Index Method in Efficiency. The Index method developed by Bhattacharya (1997) has been used to achieve this purpose. In order to fulfill the purpose of the study, the Performance Index (PI), Utilization Index (UI), and Efficiency Index (EI) have been obtained by considering the quarterly data of 12 technology companies out of 19 companies operated in the BIST for the years 2009-2019 period. The performance index, which is one of the three variables used in the index method, shows the average performance of various accounts within the assets. The other variable, the utilization index, measures the ability to increase sales by utilizing current assets. The last variable, the efficiency index, is an indicator obtained by multiplying the performance and utilization indexes (Bhattacharya, 1997, p.25). The data of the other 7 companies, which have not been included in the study, have been excluded because there were deficiencies in the data for the relevant years and some companies had not been registered with the BIST in the relevant years. In the practice part of the study, 480 data for each index and a total of 1440 data have been obtained to calculate.

The Performance Index (PI) is an index that shows the average performance of the account items in the current assets, which have a significant share in the asset structure of the business. The index has been used to 
measure the performance of current asset sub-account items of each company included in the study. In the study, four sub-headings, cash and cash equivalents, trade receivables, stocks and other current assets, which are current asset items, have been included in the analysis while calculating the index. The performance index is an index that considers the individual and performances of group members one by one (Güler \& Konuk, 2019, p.37). The Utilization Index (UI), on the other hand, is the index value that measures increase amount go business' sales by using the current assets of the business. Utilization index values are desired to be greater than 1 . If the utilization index is greater than one, it can be concluded that working capital has been managed effectively. The formula used in the calculation of the utilization index is given in Table 2. The total performance of the group is represented by the utilization index (Güler \& Konuk, 2019, p.36). The efficiency index (EI), on the other hand, is the final indicator of whether working capital is used effectively or not. The efficiency index represents a value obtained by multiplying the performance and utilization index. It is desired that the efficiency index value be greater than 1 . If the index value is greater than 1 , it can be concluded that working capital has been managed effectively (Göker, 2018, p.74).

The data obtained from the practice part of the study can be summarized as follows. In the average value of the Utilization Index (UI), it has been determined that NETAŞ company with the code 11 has the highest average index value (1.40), while ALC company is in the second place with its average index value (1.35), and ASELS is in the third place. The number of companies with the lowest utilization index value (1.23) is more than one and it is seen that they are ARENA, ARMADA, DGATE, INDES companies, respectively. Calculation of the utilization index value as greater than 1 , means that if the companies invest in their current assets as a whole, the sales revenue of the business increases.

In the average value of the Performance Index (PI), it has been determined that ALC Company has the highest average index value (1.88), while NETAŞ company is in the second place with its average index value (1.63). The company with the lowest performance index value has been determined as the INDES company with its average index value (1.28). When the averages of performance index values are evaluated as a whole, it has been determined that the average values of all companies are greater 
than 1. This means that all of the companies invest in the current asset subgroups at the right rate and the investments made increase the sales revenue.

The efficiency index value indicates whether the current assets are used effectively and efficiently, both collectively and separately for each item in the current assets group. It is seen that the efficiency index values are greater than 1 and all of them are at the value of 2 or more. When the efficiency index values of the companies that are the subject of the study have been analyzed on a company basis, it has been seen that ALC company takes the first place with its average index value (3.53), and NETAŞ company is on the second place with its average index value (3.02). The INDES company, on the other hand, has been determined as the company with the lowest index average, as well as the utilization and performance index value.

In the conclusion part of the study, it has been determined that the index values of all companies are greater than 1, therefore, investments made in current assets increase sales revenue. In addition, it has been determined that the companies with the highest efficiency as: In terms of utilization index is NETAŞ company, in terms of performance index value ALC company, and ALC company again in terms of efficiency index. On the other hand, it has been concluded that INDES company has the lowest working capital index value among existing companies in all index average values.

\section{Kaynakça / References}

Afza, T. and Nazir, M. S. (2011). Working Capital management efficiency of cement sector of Pakistan. Journal of Economies and Behavioral Studies, 2(5), 223-235.

Aytürk, Y ve Yanık, S . (2015). Çalışma sermayesi yönetimi Türkiye'deki KOBİ'lerde karlılığı nasıl etkiler? Muhasebe ve Finansman Dergisi , 68 , 157-168. DOI: 10.25095/mufad.396631

Bhattacharya, H. (1997), Total Management by Ratios. New Dehli: Sage Publications.

Brigham, E. F. and Houston, J. F. (2007). Fundamentals of financial management Mason. OH USA: Thomson South-Westem. 
Eljelly, Abuzar, (2004). Liquidity-profitability tradeoff: an empirical investigation in an emerging market. International Journal of Commerce $\mathcal{E} M a-$ nagement, $14(2), 48-61$.

Erem Ceylan, I. (2020). İşletme sermayesi yönetiminin verimliliğinin ölçülmesi: İndeks yöntemi. Economics Business and Organization Research, Proceedings of the Third Economics, Business And Organization Research (EBOR) Conference, 238-246.

Göker, İ. E. K. (2018) Çalışma sermayesi yönetiminde etkinlik durumunun tespiti: Bist gıda sektörü firmaları üzerine bir araştırma. Uluslararası Yönetim Eğitim ve Ekonomik Perspektifler Dergisi, 6(3), 69-79.

Güler, E. ve Konuk, F. (2019). Çalışma sermayesi etkinlik ölçümünde alternatif bir araç: İndeks yöntemi. Muhasebe ve Finansman Dergisi, 84, 35-48.

Kasiran F. W., Mohamad N. A. and Chin O. (2016). Working capital management efficiency: A study on the small medium enterprise in Malaysia. Procedia Economics and Finance, 35, 297-303.

Kaur H. V. and Singh S. (2013). Managing working capital efficiency in capital goods sector in India. Global Business Review, 14(2), 343-355.

Kaur, H. V. (2014). Efficient management of working capital: A study of heathcare sector in India. Management Strategies Journal, Constantin Brancoveanu University, 25(3), 53-65.

Kendirli, S ve Çankaya, M. (2016). Bist turizm indeksindeki şirketlerde işletme sermayesi yönetiminin karlılık üzerindeki etkisini ölçmeye yönelik bir araştırma. International Review of Economics and Management, 4(2), 46-68.

Öz, Y. ve Güngör, B. (2007). Çalışma sermayesi yönetiminin firma kârlılığ üzerine etkisi: İmalat sektörüne yönelik panel veri analizi. Atatürk Üniversitesi Sosyal Bilimler Enstitüsü Dergisi, 10(2), 319-332.

Ramachandran A. and Janakiraman M. (2009). The relationship between working capital management efficiency and EBIT. Managing Global Transitions International Reseacrh Journal, 7(1), 61-74.

Sakarya, Ş. (2008). Nakit yönetiminde nakit dönüş süresi analizinin kullanılması: İmkb'deki Kobi'ler üzerine ampirik bir çalışma. Suleyman Demirel University Journal of Faculty of Economics \& Administrative Sciences, 13(2), 228.

Sharma, A. K. and Kumar, S. (2011). Effect of working capital management on firm profitability: Empirical evidence from India. Global Business Review, 12(1), 159-173. 
Toraman, C. ve Sönmez, A.R. (2015). Çalışma sermayesi ve karlılık arasındaki ilişki: Perakende Ticaret sektörü üzerine bir uygulama. Erzincan Üniversitesi Sosyal Bilimler Enstitüsü Dergisi (ERZSOSDE), VIII(I), 15-24.

Yücel, T. and Kurt, G. (2002). Nakit dönüş süresi, nakit yönetimi ve kârlılık: İMKB şirketleri üzerinde ampirik bir çalışma. İMKB Dergisi, 6(22), 115.

www.kap.org.tr/Kamuyu Aydınlatma Platformu, Erişim Tarihi: 03.03.2020. https://wwww.kalkinmakutuphanesi.gov.tr/ Bilişim ve Sektör Raporu 2019, Erişim Tarihi: 03.07.2021.

https://www.hurriyet.com.tr/ekonomi/iste-turkiyede-gelecek-vaat-eden-sektorler10278823 Erişim Tarihi:22.07.2021.

\section{Kaynakça Bilgisi / Citation Information}

Mazman İtik, İ. (2021). Çalışma sermayesi etkinlik ölçümünde indeks yöntemi: Teknoloji şirketlerinde bir uygulama. OPUS-Uluslararası Toplum Araştırmaları Dergisi, 18(41), 3534-3551. DOI: 10.26466/opus. 909470. 